\title{
Fading and graphite nucleation sites in grey iron inoculated using silicon carbide
}

\author{
Harold Machado González ${ }^{1}$, Paula Pérez Espitia ${ }^{1}$,
} Ricardo Aristizábal Sierra ${ }^{1}$

\author{
${ }^{1}$ Grupo GIPIMME, Departamento de Ingeniería Metalúrgica y de Materiales, Facultad de Ingeniería, Universidad de \\ Antioquia, Medellín-Colombia \\ email: harold.machado@udea.edu.co,pandrea.perez@udea.edu.co,ricardo.aristizabal@udea.edu.co
}

\begin{abstract}
The most commonly used inoculants for producing grey iron are ferrosilicon based, but also there are reports indicating that silicon carbide can act as inoculant. There are few published studies of fading and nucleation sites of graphite when silicon carbide is used as inoculant, thus the understanding of the inoculation effect of silicon carbide is incomplete. To study these two aspects, fading and graphite nucleation sites, an ASTM class 35B grey iron inoculated with silicon carbide was produced and characterized. The results were compared with an ASTM class 35B grey iron inoculated with a ferrosilicon base inoculant and without inoculation. It was found that the effect of the silicon carbide was comparable to the ferrosilicon base inoculant and fading was similar. In addition, the graphite nucleation sites in the grey iron inoculated with silicon carbide were irregular shaped manganese sulfides larger than the nuclei in the grey iron inoculated with ferrosilicon, which suggest a similar nucleation mechanism for both inoculants.
\end{abstract}

Keywords: Grey iron, inoculation, silicon carbide, fading, graphite nuclei.

\section{INTRODUCTION}

Grey iron is widely used due to its good mechanical properties, thermal conductivity, damping capacity, castability and low cost. The mechanical properties of grey iron depend directly on its microstructure, which is related with processing variables such as chemistry, solidification rate, charge materials and inoculation $[1,2]$.

Inoculation provides sites for heterogeneous nucleation, which increases the amount of eutectic cells leading to a finer microstructure. Also, it decreases undercooling, making the solidification temperature closer to a stable equilibrium, which favors the precipitation of graphite instead of carbides [3]. Thus inoculation provides grey iron with better mechanical properties, such as, higher hardness and higher tensile strength [46].The most commonly used inoculants are ferrosilicon based containing one or more of these elements: barium, calcium, zirconium, strontium, cerium and aluminum, among others. Researches indicate that the most common graphite nucleation sites are small $\mathrm{Al}_{2} \mathrm{O}_{3}$-based sites surrounded by a complex $(\mathrm{Mn}, \mathrm{X}) \mathrm{S}$ compound (X: Al, O, Si, Ca, Ba, Sr...). The role of the inoculation chemical elements is to transform sulfides in complex compounds with a low crystallographic misfit with graphite, good stability, adequate interfacial energy and higher melting point [6-10].

Silicon carbide can also be used as an inoculant with results similar to those obtained with ferrosilicon base inoculants [11-15]. Edalati et al. studied the effect of silicon carbide as inoculant and as silicon carrier in grey iron poured at different temperatures, the results showed that using $\mathrm{SiC}$ as inoculant increased the liquid and eutectic temperatures, type A graphite and eutectic cell count and decreases undercooling and chill depth [12-13]. Schubert et al. indicate that the high melting point of silicon carbide allows it to dissolve slowly into the molten metal, leading to local hypereutectic regions where carbon clusters are formed, these clusters act as the seed for later graphite formation [14]. Benecke reported that using silicon carbide to produce cast iron has positive effects increasing the eutectic cells counting, the tensile strength-hardness relationship, machinability and microstructural homogeneity of the casting [15]. Wang and Fredrickson hypothesized that SiC and graphite particles are metastable products of ferrosilicon addition to liquid iron, and that the dissolution of these metastable products generates local carbon and silicon supersaturated regions that promotes homogeneous nucleation of graphite [16,17]. 
Another important consideration when producing grey iron is fading, which consists of the loss of the inoculation effect with time, which increases undercooling during solidification, favors the formation of carbides instead of graphite, increases hardness and decreases tensile strength. Fading and graphite nucleation sites have been studied widely for grey iron inoculated with ferrosilicon base inoculants, however there are few published reports of these topics for materials inoculated with silicon carbide which limits the understanding of its inoculation effect.

\section{MATERIALS AND METHODS}

Eight kilograms $(8 \mathrm{~kg})$ heats of the alloys were produced in an induction furnace using as charge materials grey iron, cold rolled steel, graphite and ferrosilicon. Samples for chemical and thermal analysis were obtained before inoculation (BI), after inoculation (AI) and seven, fourteen and twenty minutes after inoculation. Chemistry was determined by optical emission spectroscopy (OES) of chilled samples, carbon was determined using a carbon Leco analyzer. Temperature of the alloy was measured at the furnace before transfer to the pouring ladle (see Table 1). The inoculants were added to the molten metal stream during transfer from the furnace to the pouring ladle. Two inoculants were evaluated, silicon carbide and a ferrosilicon base inoculant. Chemistry of the inoculants was determined using x ray fluorescence (see Table 2). Particle size of the inoculants was $2.6 \mathrm{~mm}-3.0 \mathrm{~mm}$ and $0.3 \mathrm{wt} \%$ of inoculation was used. Two replicates of each experiment were performed.

Table 1: Chemical composition of grey iron samples and temperature at the furnace.

\begin{tabular}{|c|c|c|c|c|c|c|c|c|c|c|}
\hline \multirow{2}{*}{ RUN } & \multirow{2}{*}{ REPLICATE } & \multirow{2}{*}{$\begin{array}{c}\text { TIME, } \\
\text { MINUTES }\end{array}$} & \multirow{2}{*}{$\begin{array}{c}\text { TEMPERATURE, } \\
{ }^{\circ} \mathrm{C} \\
\end{array}$} & \multicolumn{7}{|c|}{ WEIGTH\% } \\
\hline & & & & C & $\mathrm{Si}$ & Mn & $\mathrm{s}$ & $\mathbf{P}$ & Al & $\mathrm{CE}$ \\
\hline \multirow{10}{*}{$\mathrm{SiC}$} & \multirow{5}{*}{1} & $\mathrm{BI}^{*}$ & 1471 & 3.30 & 2.25 & 0.36 & 0.04 & 0.06 & 0.004 & 4.04 \\
\hline & & $\mathrm{AI}^{* *}$ & 1477 & 3.36 & 2.42 & 0.36 & 0.04 & 0.06 & 0.005 & 4.12 \\
\hline & & 7 & 1472 & 3.38 & 2.44 & 0.36 & 0.04 & 0.06 & 0.004 & 4.15 \\
\hline & & 14 & 1455 & 3.31 & 2.46 & 0.35 & 0.04 & 0.07 & 0.003 & 4.07 \\
\hline & & 20 & 1462 & 3.30 & 2.44 & 0.35 & 0.04 & 0.07 & 0.003 & 4.05 \\
\hline & \multirow{5}{*}{2} & $\mathrm{BI} *$ & 1456 & 3.37 & 2.19 & 0.34 & 0.12 & 0.05 & 0.003 & 4.13 \\
\hline & & $\mathrm{AI}^{* *}$ & 1443 & 3.37 & 2.21 & 0.34 & 0.14 & 0.05 & 0.003 & 4.15 \\
\hline & & 7 & 1461 & 3.40 & 2.25 & 0.33 & 0.09 & 0.05 & 0.003 & 4.19 \\
\hline & & 14 & 1464 & 3.36 & 2.23 & 0.34 & 0.10 & 0.05 & 0.003 & 4.14 \\
\hline & & 20 & 1467 & 3.36 & 2.19 & 0.33 & 0.19 & 0.05 & 0.003 & 4.16 \\
\hline \multirow{10}{*}{$\mathrm{FeSi}$} & \multirow{5}{*}{1} & $\mathrm{BI}^{*}$ & 1462 & 3.39 & 2.25 & 0.35 & 0.10 & 0.06 & 0.002 & 4.16 \\
\hline & & $\mathrm{AI}^{* *}$ & 1472 & 3.39 & 2.40 & 0.34 & 0.10 & 0.06 & 0.004 & 4.22 \\
\hline & & 7 & 1451 & 3.35 & 2.37 & 0.34 & 0.09 & 0.06 & 0.003 & 4.18 \\
\hline & & 14 & 1455 & 3.30 & 2.36 & 0.34 & 0.09 & 0.06 & 0.002 & 4.14 \\
\hline & & 20 & 1467 & 3.25 & 2.42 & 0.34 & 0.17 & 0.07 & 0.003 & 4.08 \\
\hline & \multirow{5}{*}{2} & $\mathrm{BI}^{*}$ & 1465 & 3.37 & 2.28 & 0.36 & 0.10 & 0.06 & 0.003 & 4.14 \\
\hline & & $\mathrm{AI}^{* *}$ & 1460 & 3.37 & 2.46 & 0.36 & 0.12 & 0.06 & 0.004 & 4.19 \\
\hline & & 7 & 1466 & 3.30 & 2.47 & 0.35 & 0.14 & 0.07 & 0.003 & 4.11 \\
\hline & & 14 & 1470 & 3.31 & 2.43 & 0.35 & 0.09 & 0.06 & 0.003 & 4.11 \\
\hline & & 20 & 1466 & 3.30 & 2.50 & 0.35 & 0.10 & 0.07 & 0.003 & 4.12 \\
\hline
\end{tabular}

*BI: Before Inoculation, **AI: After Inoculation.

Table 2: Chemical composition of the inoculants, wt $\%$.

\begin{tabular}{c|c|c|c|c|c|c|c|c|c|c|c|c}
\hline INOCULANT & $\mathbf{S i}$ & $\mathbf{F e}$ & $\mathbf{C}$ & $\mathbf{C a}$ & $\mathbf{B a}$ & $\mathbf{A l}$ & $\mathbf{M n}$ & $\mathbf{Z r}$ & $\mathbf{T i}$ & $\mathbf{S r}$ & $\mathbf{C u}$ \\
\hline $\mathrm{SiC}$ & 69.4 & - & 29.4 & 0.25 & - & 0.02 & 0.03 & 0.03 & 0.02 & - & 0.02 \\
\hline $\mathrm{FeSi}$ & 80.2 & 17.0 & - & 0.73 & 0.74 & 0.48 & 0.22 & 0.20 & 0.07 & 0.02 & 0.03 \\
\hline
\end{tabular}


Stable and metastable eutectic temperatures were calculated according with eq. (1) and (2) [18]. First derivative of the cooling curve was used for thermal analysis according to references $[18,19]$.

$$
\begin{gathered}
T_{s t}=1154^{\circ} \mathrm{C}+6.7(\% S i)-2(\% M n)-30(\% P)+5(\% C u)+4(\% N i) \\
T_{m s t}=1148^{\circ} \mathrm{C}-12(\% S i)+3(\% M n)-37(\% P)-15(\% A l)+7(\% C r) \\
-2.3(\% C u)-6(\% N i)+7(\% V)
\end{gathered}
$$

Brinell hardness was determined according with ASTM E10 using 3000kgf and a 10mm diameter steel ball [20]. Five indentations were performed on each sample. Microstructural analysis included determining the type of graphite and the volume percent of carbides. Samples were observed using an optical microscope and prepared using standard metallographic techniques with a $1 \mu \mathrm{m}$ diamond final polish. Graphite type was determined in unetched samples according with ASTM A247 [21]. Carbides volume percent was determined by stereological measurements in samples etched with Nital 5. Twenty random fields of view were used to guarantee a percent of relative accuracy lower than $10 \%$.

Graphite nucleation sites were studied by SEM-EDS in un-inoculated samples and samples inoculated with the ferrosilicon base inoculant and silicon carbide. Finally, green sand molds were used to pour Y blocks one inch thick before inoculation, at seven and twenty minutes after inoculation. Two tensile bars were machined from each Y-Block and tested according with ASTM E8 [22].

\section{RESULTS AND DISCUSSION}

\subsection{Microstructure}

As expected, before inoculation graphite was preferentially type D, also some type A and C graphite were detected. Microstructural analysis of the samples after inoculation and seven minutes after inoculation showed preferentially type A graphite. At fourteen and twenty minutes after inoculation the amount of type A graphite decreased and the amount of type D graphite increased, which indicated that fading was taking place. Figure 1 shows representative micrographs of the unetched samples. The matrix was pearlitic with traces of ferrite in some areas close to the graphite flakes.

(n)




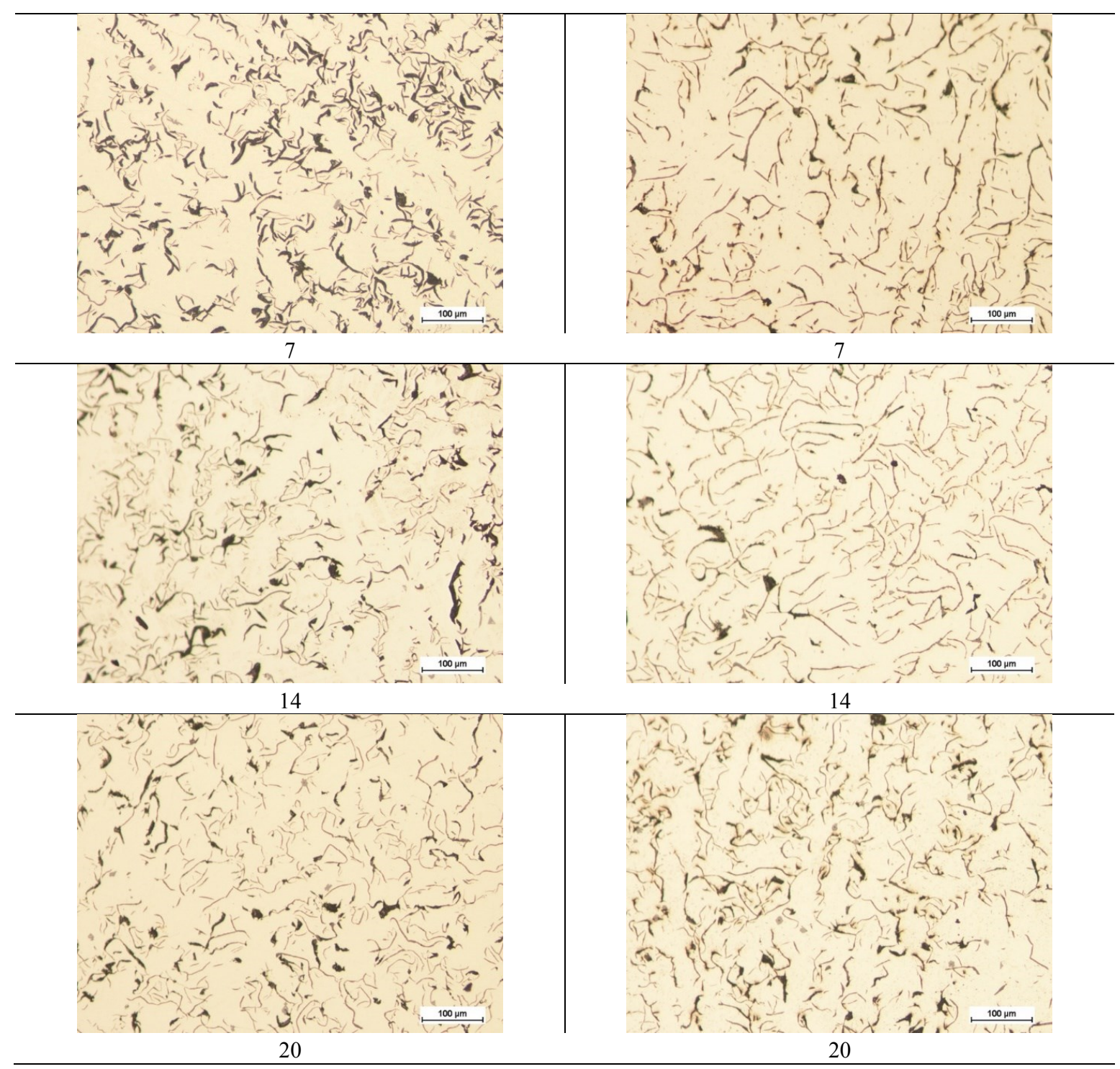

Figure 1: Representative micrographs of unetched grey iron samples.

There was no significant statistical difference in the volume percent of carbides between both inoculants. Around $4 \mathrm{vol} \%$ of carbides were found in the samples before inoculation, after inoculation carbides decreased to around $2 \mathrm{vol} \%$. The results showed as expected, that the amount of carbides increased with time after inoculation as a consequence of fading. The results of the quantification of the volume percent of carbides can be seen in figure 2 .

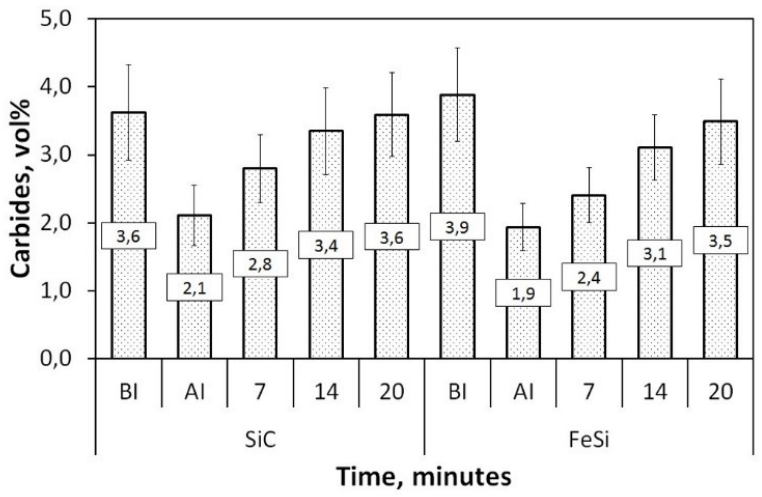

Figure 2: Results of the quantification of carbides. 


\subsection{Tensile strength and hardness}

The results showed that both inoculants had similar effects in hardness and tensile strength of the alloy (Figure 3). Inoculated grey irons were Class 35B according to ASTM specification A48 for both inoculants, ferrosilicon and silicon carbide [23]. Also fading for both inoculants was comparable and started to be detected at fourteen minutes after inoculation. Silicon carbide showed a slightly higher effect decreasing hardness than ferrosilicon, which is explained by the additional carbon in the silicon carbide that slightly increased the carbon concentration in the alloy. For both inoculants, the lowest hardness was obtained in the samples taken seven minutes after inoculation. At fourteen and twenty minutes after inoculation, hardness was at the same level than before the inoculation, which agrees with the microstructural changes discussed early. As expected, tensile strength increased after inoculation and then decreased with time because of fading. The grey iron inoculated with ferrosilicon showed a slightly higher increase in strength than the alloy inoculated with silicon carbide, which is explained also by the small differences in carbon concentration. The results obtained in the samples taken twenty minutes after inoculation were comparable with the results obtained in the uninoculated material.

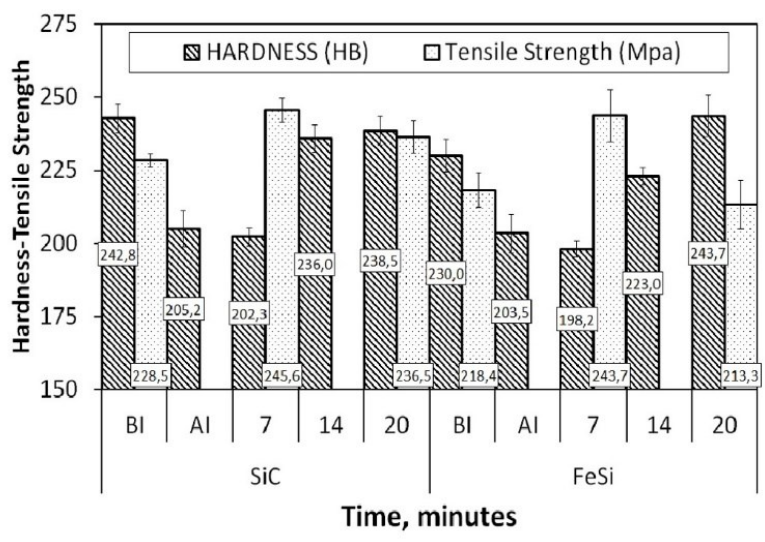

Figure 3: Variation of hardness and tensile strength with time for both inoculants.

\subsection{Thermal analyses}

The effect of inoculation with silicon carbide on the cooling curves during solidification was similar to the effect of inoculation with the ferrosilicon base inoculant. For both inoculants, the results agree with previous published results of other authors, which indicate that the main effect of inoculation is to increase the temperature of eutectic undercooling (TEU) and the temperature of graphite recalescence (TER), also it decreases eutectic undercooling $\left(\Delta \mathrm{T}_{\mathrm{m}}\right)$ and graphite recalescence $\left(\Delta \mathrm{T}_{\mathrm{r}}\right)[18,19]$. Figure 4 shows a group of representative cooling curves of grey irons inoculated with ferrosilicon and silicon carbide, as explained before, the samples were obtained before and after inoculation and seven fourteen and twenty minutes after inoculation. The results are summarized in table 3 . 

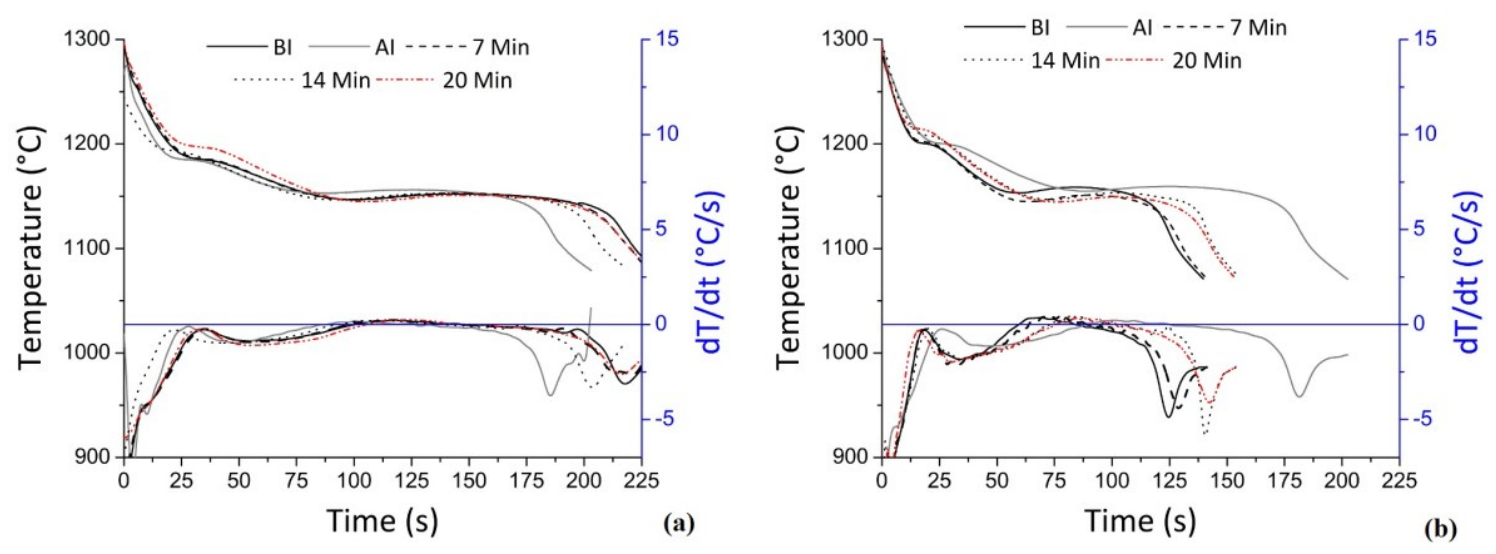

Figure 4: Representative cooling curves during solidification for grey iron inoculated with (a) ferrosilicon base inoculant and (b) silicon carbide.

After inoculation, the stable eutectic temperature $\left(\mathrm{T}_{\mathrm{st}}\right)$ increased and the metastable eutectic temperature $\left(T_{m s t}\right)$ decreased, as expected because of the increase in silicon concentration of the alloys. As a consequence, the range of eutectic equilibrium was wider and favored the growth of the graphite flakes.

Eutectic undercooling $\left(\Delta \mathrm{T}_{\mathrm{m}}\right)$ and eutectic recalescence $\left(\Delta \mathrm{T}_{\mathrm{r}}\right)$ decreased after inoculation with both, silicon carbide and ferrosilicon. $\Delta \mathrm{T}_{\mathrm{m}}$ decreased because TEU increased, which indicates that solidification happened at temperatures closer to $\mathrm{T}_{\mathrm{st}}$, favoring the formation of graphite instead of iron carbides. The values of $\Delta \mathrm{T}_{\mathrm{r}}$ after inoculation indicate a lower tendency to the early expansion of graphite and to the contraction of the primary phases, which decreases microshrinkage $[18,19]$.

The difference between TEU and $\mathrm{T}_{\mathrm{mst}}$ is $\Delta \mathrm{T}_{1}$ and the difference between the temperature of eutectic recalescence (TER) and $\mathrm{T}_{\mathrm{mst}}$ is $\Delta \mathrm{T}_{2}$. Both, $\Delta \mathrm{T}_{1}$ and $\Delta \mathrm{T}_{2}$, are related to the efficiency of the inoculants. Values of $\Delta \mathrm{T}_{1}$ and $\Delta \mathrm{T}_{2}$ lower than $20^{\circ} \mathrm{C}$ indicate a tendency to the formation of iron carbides because solidification takes place at a temperature closer to $\mathrm{T}_{\mathrm{mst}}[18,19]$. The results showed values of $\Delta \mathrm{T}_{1}$ and $\Delta \mathrm{T}_{2}$ higher than $20^{\circ} \mathrm{C}$ for all the conditions evaluated, also $\Delta \mathrm{T}_{1}$ and $\Delta \mathrm{T}_{2}$ decreased with time after inoculation.

Table 3: Results of the thermal analysis $\left({ }^{\circ} \mathrm{C}\right)$.

\begin{tabular}{|c|c|c|c|c|c|c|c|c|c|c|}
\hline INOCULANT & $\begin{array}{c}\text { TIME, } \\
\text { MINUTES }\end{array}$ & $\mathbf{T}_{\mathrm{st}}$ & $\mathbf{T}_{\mathrm{mst}}$ & TEU & TER & ${ }^{*} \Delta \mathrm{T}_{\mathrm{S}}$ & ${ }^{*} \Delta T_{m}$ & ${ }^{*} \Delta \mathrm{T}_{\mathrm{r}}$ & ${ }^{*} \Delta \mathrm{T}_{1}$ & ${ }^{*} \Delta \mathrm{T}_{2}$ \\
\hline \multirow{5}{*}{$\mathrm{SiC}$} & SI & 1168.4 & 1119.0 & 1150.1 & 1155.6 & 49.4 & 18.3 & 5.5 & 31.1 & 36.6 \\
\hline & DI & 1168.7 & 1118.4 & 1154.0 & 1157.9 & 50.3 & 14.7 & 3.9 & 35.6 & 39.5 \\
\hline & 7 & 1169.2 & 1117.7 & 1145.9 & 1151.8 & 51.5 & 23.3 & 5.9 & 28.3 & 34.2 \\
\hline & 14 & 1168.7 & 1118.4 & 1146.8 & 1153.2 & 50.4 & 21.9 & 6.4 & 28.4 & 34.8 \\
\hline & 20 & 1168.8 & 1118.2 & 1144.3 & 1150.3 & 50.7 & 24.5 & 6.0 & 26.1 & 32.1 \\
\hline \multirow{5}{*}{$\mathrm{FeSi}$} & SI & 1168.8 & 1118.0 & 1149.0 & 1155.2 & 50.8 & 19.8 & 6.2 & 31.0 & 37.2 \\
\hline & DI & 1169.9 & 1116.4 & 1152.5 & 1154.8 & 53.5 & 17.4 & 2.3 & 36.1 & 38.4 \\
\hline & 7 & 1169.9 & 1116.2 & 1149.4 & 1156.1 & 53.7 & 20.5 & 6.7 & 33.2 & 39.9 \\
\hline & 14 & 1169.9 & 1116.0 & 1141.2 & 1146.5 & 53.9 & 28.8 & 5.3 & 25.1 & 30.4 \\
\hline & 20 & 1170.0 & 1115.7 & 1142.9 & 1148.3 & 54.4 & 27.1 & 5.4 & 27.3 & 32.7 \\
\hline
\end{tabular}

${ }^{*} \Delta \mathrm{T}_{\mathrm{s}}=\mathrm{T}_{\mathrm{st}}-\mathrm{T}_{\mathrm{mst}}, \Delta \mathrm{T}_{\mathrm{m}}=\mathrm{T}_{\mathrm{st}}-\mathrm{TEU}, \Delta \mathrm{T}_{\mathrm{r}}=\mathrm{TER}-\mathrm{TEU}, \Delta \mathrm{T}_{1}=\mathrm{TEU}-\mathrm{T}_{\mathrm{mst}}, \Delta \mathrm{T}_{2}=\mathrm{TER}-\mathrm{T}_{\mathrm{mst}}$

\subsection{Graphite nucleation sites}

The results of the SEM-EDS analysis showed that the graphite nucleation sites were manganese and sulfur rich particles. Also oxygen, aluminum, calcium, silicon and zirconium were detected at the nuclei. Figure 5(a) shows a representative chemical profile of a particle where a type D graphite nucleated in un-inoculated grey iron. Oxygen, aluminum and silicon were detected in the center and manganese and sulfur were found in the outer shell. The results indicate that the particle is a manganese sulfide that nucleated on an aluminum 
silicon oxide or an aluminum silicate. The nucleation sites for type D graphite were $2 \mu \mathrm{m}-5 \mu \mathrm{m}$ size and regular shaped.

The nucleation sites of type A graphite in the grey iron inoculated with ferrosilicon were $2 \mu \mathrm{m}-4 \mu \mathrm{m}$ size with regular morphologies (see figure 5(b)). The results indicated that the nucleation sites were complex manganese sulfides of the type $(\mathrm{Mn}, \mathrm{X}) \mathrm{S}, \mathrm{X}=\mathrm{Ca}, \mathrm{Zr}, \mathrm{Al}, \mathrm{Si}$, O, which agrees with previous studies [6]. According to Riposan et al. the heterogeneous nucleation of graphite in grey iron requires non metallic inclusions. These inclusions need to have a negative enthalpy of formation, a melting temperature higher than iron and a crystalline structure compatible with graphite. These inclusions already exist in the liquid iron and are activated by the inoculation process. Inclusions such as silicates, oxides, sulfides, carbides and nitrides can nucleate graphite. Silicates and oxides have the best chemical affinity with graphite, however the low oxygen concentration in the molten metal diminish the probability of this kind of events, thus nucleation happens mainly at manganese sulfides, which increase their chemical affinity with graphite and their melting temperature when chemical elements like calcium, zirconium and aluminum are added to form complex sulfides of the $(\mathrm{Mn}, \mathrm{X}) \mathrm{S}$ type $[6,8,9]$.

The analysis of the grey iron inoculated with silicon carbide showed that type A graphite nucleated also at manganese sulfides. Oxygen, silicon and aluminum were detected at the center and the core of the nuclei as well (figure 5(c)). The nucleation particles for silicon carbide had irregular morphologies and were between $8 \mu \mathrm{m}-10 \mu \mathrm{m}$ size. The results suggest that when silicon carbide is used as inoculant, the graphite nucleation mechanism is similar to the mechanism when ferrosilicon base inoculants are used, i.e., graphite nucleates heterogeneously on manganese sulfides. However, the absence of the inoculation chemical elements seems to propitiate larger irregular shaped nuclei. As suggested by other authors, the slow dissolution of $\mathrm{SiC}$ in the liquid iron may be playing an important role in the inoculation effect of $\mathrm{SiC}$, because it promotes carbon and silicon microsegregation in the melt [14-17]. Graphite formation is favored at the areas where silicon and carbon concentration are high, while austenite nucleation is promoted at the areas where their concentration is low. Also, fading when silicon carbide is used as inoculant may be associated with carbon and silicon diffusion over time, which eliminates microsegregation.

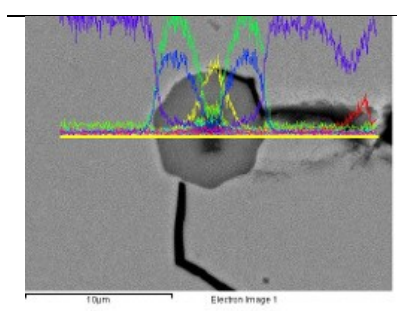

BSE Image

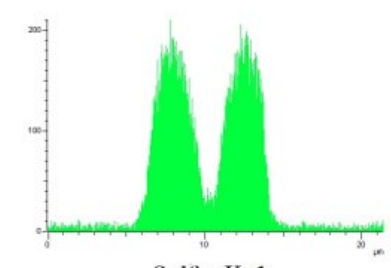

Sulfur Ka1

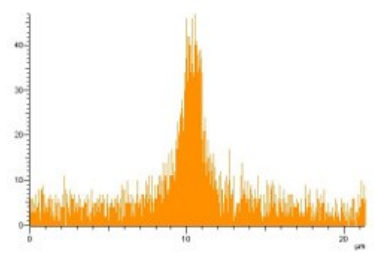

Oxygen $\mathrm{Kal}$

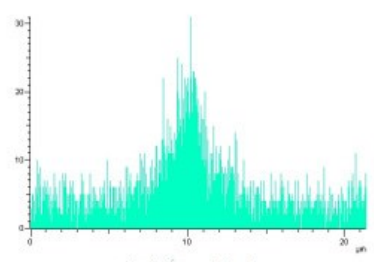

Calcium Kal

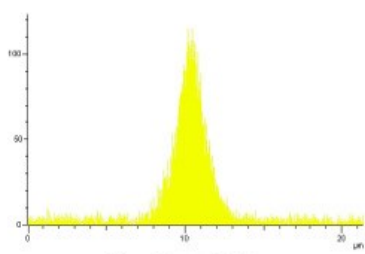

Aluminum Kal

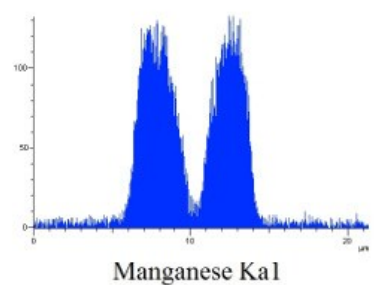

Manganese Kal

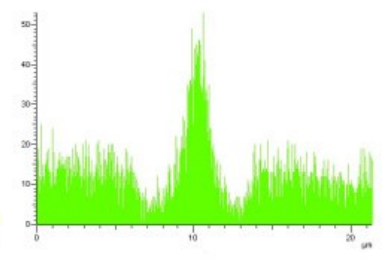

Silicon Ka 1

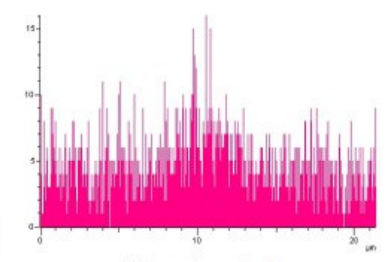

Zirconium Lal

(a) 

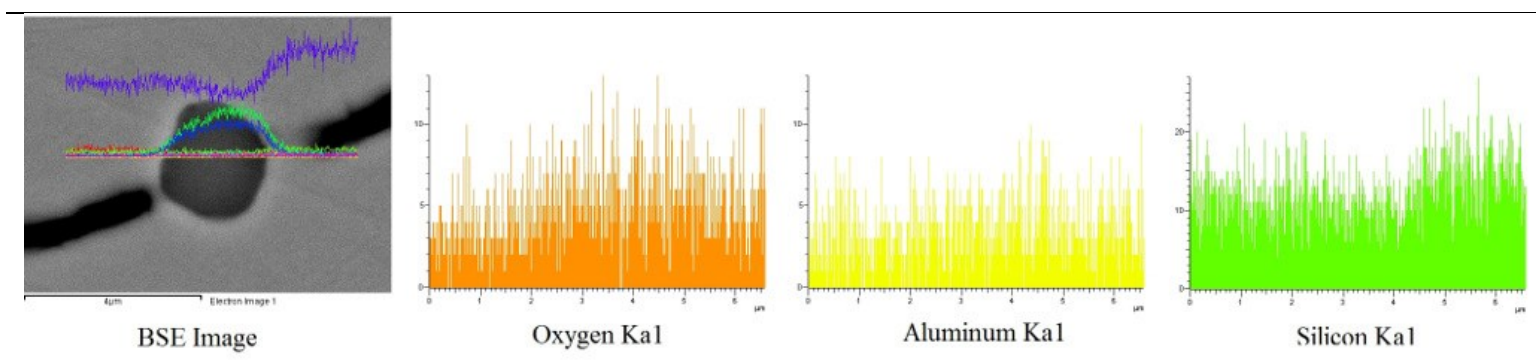

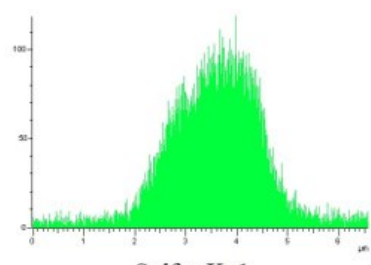

Sulfur Kal

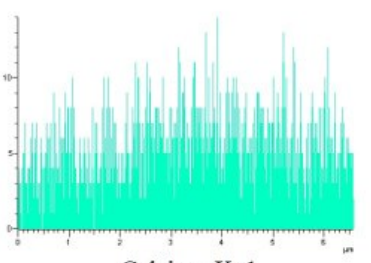

Calcium Kal

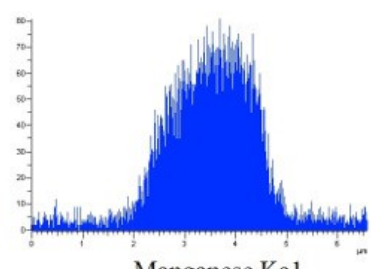

Manganese Kal

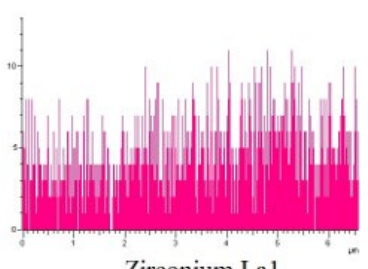

Zirconium Lal

(b)

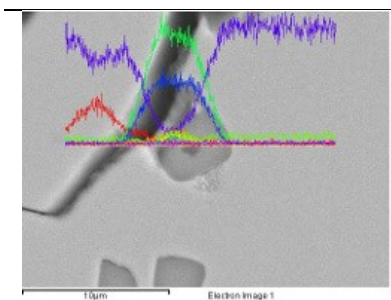

BSE Image

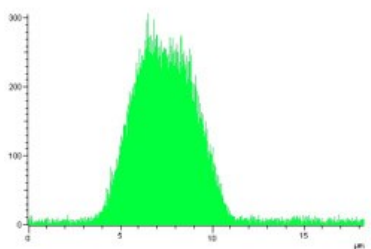

Sulfur Ka1

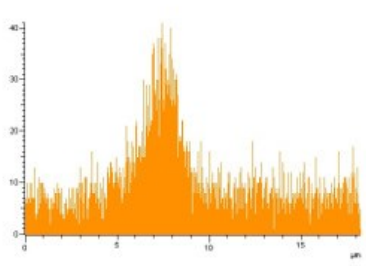

Oxygen Kal

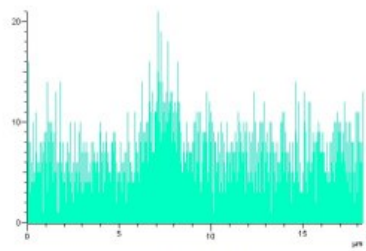

Calcrum Kal

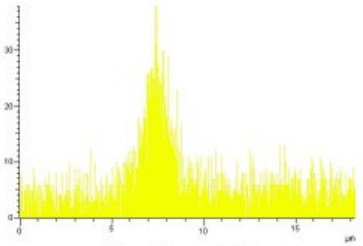

Aluminum Ka1

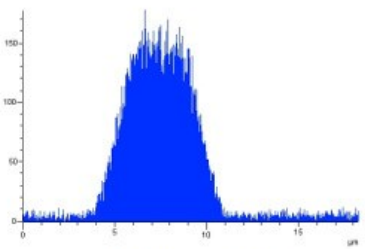

Manganese Kal

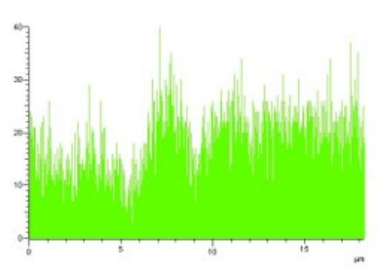

Silicon Ka1

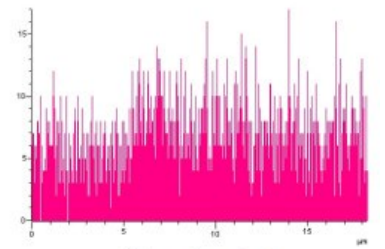

Zirconium Lal

(c)

Figure 5: Representative results of the analysis of the nuclei. (a) Type D graphite in grey iron before inoculation. (b) Type A graphite in grey iron inoculated with a ferrosilicon base inoculant. (c) Type A graphite in grey iron inoculated with silicon carbide.

\section{SUMMARY AND CONCLUSIONS}

Silicon carbide used as inoculant gives fading times comparable to the fading time obtained with ferrosilicon base inoculants. In the present study fading started to be detected at fourteen minutes after inoculation. As it happens with other inoculants, fading affects the solidification conditions with the concomitant effect in microstructure, hardness and strength. The graphite nucleation mechanism when silicon carbide is used as inoculant is similar to the mechanism when ferrosilicon base inoculants are used, i.e., graphite flakes nucleate at aluminum oxides surrounded by complex manganese sulfides. However, the absence of the inoculation chemical elements when silicon carbide acts as inoculant produce large irregular shaped nuclei, which seems to be compensated by carbon and silicon microsegregation in the molten metal promoted by the slow dissolution of silicon carbide compared with ferrosilicon.

\section{AKNOWLEDGEMENTS}

The authors would like to acknowledge the financial support of the Research Vice Rectory of the University of Antioquia under Project CODI-MDC10-1-02 and the Sustainability Strategy of the University of Antioquia 2014-2015. 


\section{BIBLIOGRAPHY}

[1] STEFANESCU, D. M "Classification and Basic Metallurgy of Cast Iron," in: ASM Handbook, v.1. Properties and Selection: Irons, Steels, and High-Performance Alloys, USA, ASM International, pp. 3-11, 1999.

[2] DAVIS, J. R. “Classification and Basic Metallurgy of Cast Iron”, In: ASM Speciality Handbook: Cast Irons,, ASM-INTERNATIONAL, USA, pp. 3-15, 1996.

[3] STEFANESCU, D. M, “Solidification of Eutectic Alloys: Cast iron”, In: ASM Handbook, v.15. pp.168181. USA, ASM International, 1999.

[4] RIPOSAN, I., CHISAMERA, M., STAN, S., et al., "Complex (Mn, X)S compounds - major sites for graphite nucleation in greycast iron”, China Foundry, v. 6, pp. 352-357, 2009.

[5] HARVEY, J.N., NOBLE, G.A. “Inoculation of Cast Irons: An Overview”, In: The 55th Indian Foundry Congress, 2007.

[6] CHISAMERA, M., RIPOSAN, I., STAN, S., et al., "Inoculated Slightly Hypereutectic Gray Cast Irons", Journal of Materials Engineering and Performance, 2011, pp 331-338.

[7] CHISAMERA, M., RIPOSAN, I., STAN, S., et al., "Graphite nucleation control in grey cast iron", International Journal of Cast Metals Research, v. 21, pp. 39-44, 2008.

[8] RIPOSAN, I., CHISAMERA, M., STAN, S., et al. "A New Approach to Graphite Nucleation Mechanism in Gray Irons”, In: Proceedings of the AFS Cast Iron Inoculation Conference, pp. 31-42, 2005.

[9] RIPOSAN, I., CHISAMERA, M., STAN, S., et al., “Analyses of Possible Nucleation Sites in Ca/Sr Over-inoculated Gray Irons”, AFS Transactions, v. 109, pp. 1151-1162, 2001.

[10] BROWN, J.R. "Inoculation of grey cast iron", In: Foseco Ferrous Foundryman's Handbook, ed Oxford: Butterworth-Heinemann, pp. 62-69, 2001.

[11] PÉREZ ESPITIA, P.A., Efecto de la utilización de carburo de silicio como agente inoculante en las propiedades microestructurales y mecánicas de los hierros grises, Tesis of M Sc, Univertity of Antioquia, Medellín-Colombia, 2011.

[12] EDALATI, K., AKHLAGHI, F., NILI-AHMADABADI, M. "Influence of inoculant and/or SiC addition on characteristics of grey cast iron", International Journal of Cast Metals Research, v. 17, n. 3, pp. 147-151, 2004.

[13] EDALATI, K., AKHLAGHI, F., NILI-AHMADABADI, M. "Influence of SiC and FeSi addition on the characteristics of gray cast iron melts poured at different temperatures", Journal of Materials Processing Technology, v. 160, n. 2, pp. 183-187, 2005.

[14] SCHUBERT, W.D., TA, A.T., KAHR, G., et al., "Influence of SiC additions on the microstructure of gray cast iron", In: The Physical Metallurgy of Cast Iron: Materials Research Society V Simposia Proceedings. ed: North-Holland, pp. 119-128, 1984.

[15] BENECKE, T. "Metallurgical silicon carbide in electric and cupola furnaces", Giesserei, Translation from German, Order BCIRA T 1620, v. 68, n. 12, pp 344-349, 1981.

[16] WANG, C.H. AND FREDRIKSSON, H., "On the mechanism of inoculation of cast iron melts", In: 48th International Foundry Congress, Varna, Bulgaria, 1981.

[17] FREDRIKSSON, H. "Inoculation of Iron-base Alloys", Materials Science and Engineering, v. 65, pp. $137-144,1984$.

[18] CHISAMERA, M., STAN, S., RIPOSAN, I., et al., "Thermal analysis of inoculated grey cast irons", In: The Annals of "Dunarea de Jos" University of Galati. Fascicle Ix. Metallurgy and Materials Science, pp. 1116, 2008.

[19] STAN, S., CHISAMERA, M., RIPOSAN, I., et al., "Application of thermal analysis to monitor the quality of hypoeutectic cast irons during solidification in sand and metal moulds", In: J Therm Anal Calorim, v. 110, pp. 1185-1192, 2011.

[20] ASTM E10, Standard Test Method for Brinell Hardness of Metallic Materials. ASTM International, 2014.

[21] ASTM A247, Standard Test Method for Evaluating the Microstructure of Graphite in Iron Castings. ASTM International, 2010. 
[22] ASTM E8/E8M, Standard Test Methods for Tension Testing of Metallic Materials. ASTM International 2013.

[23] ASTM A48/A48M, Standard Specification for Grey Iron Castings, ASTM International, 2012. 